\title{
KINETICS OF THE DEPROTONATION OF METHYLNITRO- ACETATE BY Amines: UnUSUAlly High InTRinsic RATE CONSTANTS FOR A NitroAlKANE
}

Claude F. Bernasconi, Moisés Pérez-Lorenzo and Shoshana D. Brown

Supporting Information 


\section{Table of Contents}

page

Figure S1 Spectrophotometric determination of the $K_{\mathrm{a}}^{\mathrm{CH}}$ of $\mathbf{4 H}$ in water $\quad$ S3

$\begin{array}{lll}\text { Figure S2 } & \text { Plots of } k_{\text {obsd }} \text { versus amine concentration } & \text { S4 }\end{array}$

Figure S3 Plot of slopes of buffer plots versus $\mathrm{a}_{\mathrm{H}^{+}}$according to eq $8 \quad$ S5

Figure S4 Plot of intercepts of buffer plots versus $\left[\mathrm{OH}^{-}\right] \quad$ S6 


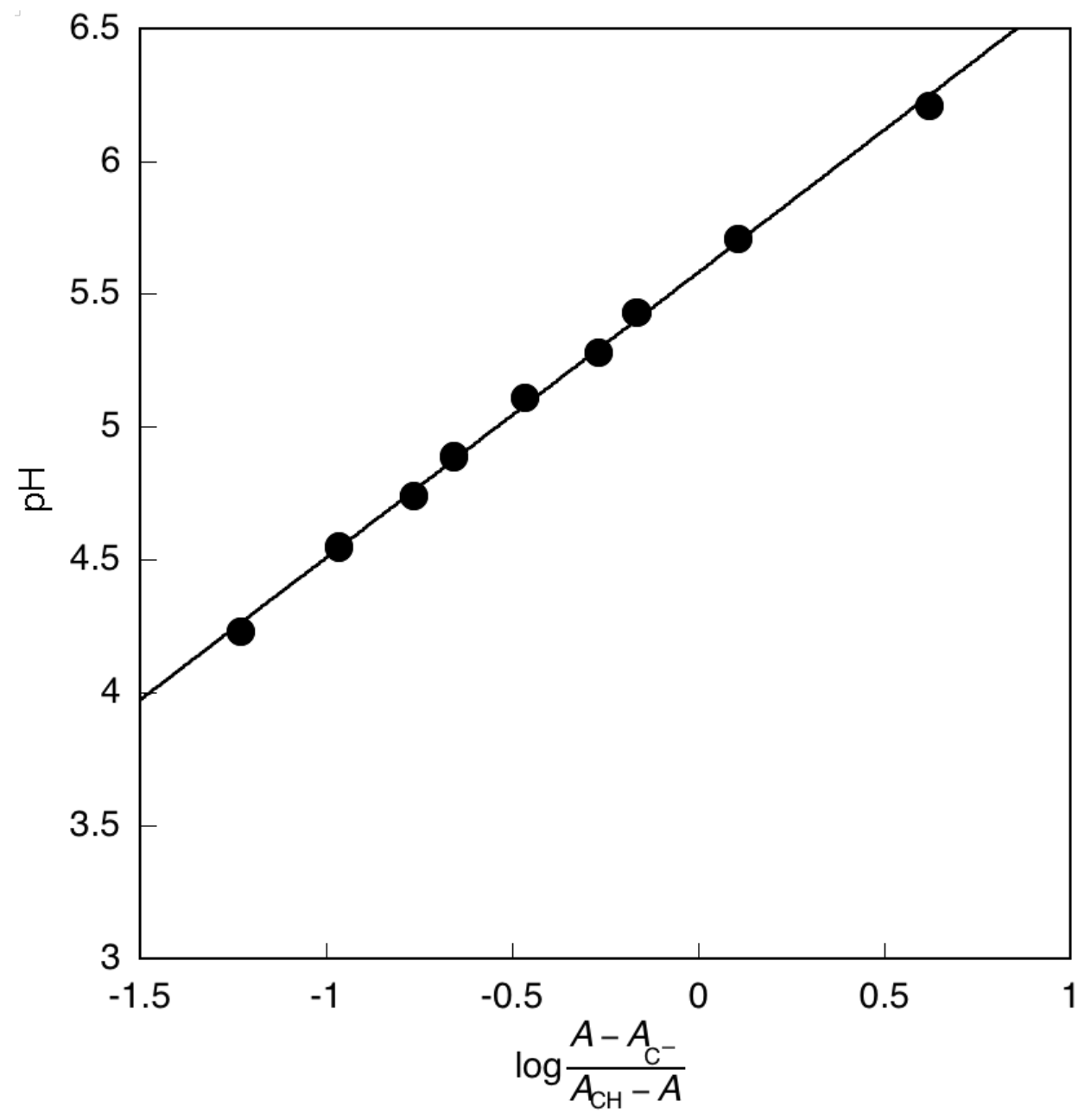

Figure S1. Spectrophotometric determination of the $\mathrm{p} K_{\mathrm{a}}^{\mathrm{CH}}$ of $\mathbf{4 H}$ in water. Plot according to eq 3 . 


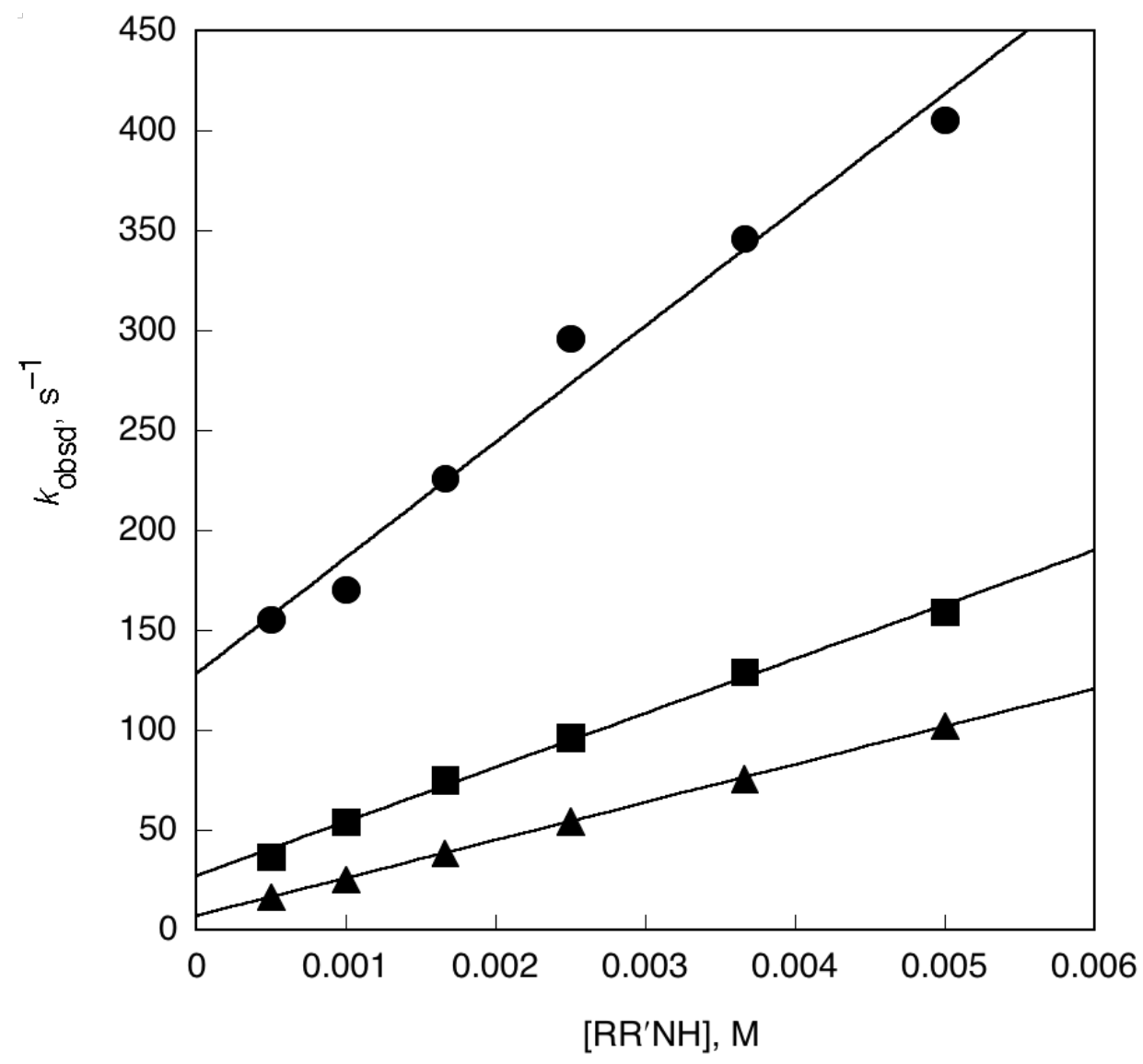

Figure S2. Plots of $k_{\text {obsd }}$ versus amine concentration according to eq 6. J, Reaction with $n$ butylamine in water at $\mathrm{pH}$ 10.78. B, Reaction with piperazine in water at $\mathrm{pH}$ 10.15. H, Reaction with $n$-butylamine in 50\% DMSO-50\% water at $\mathrm{pH} 10.61$. 


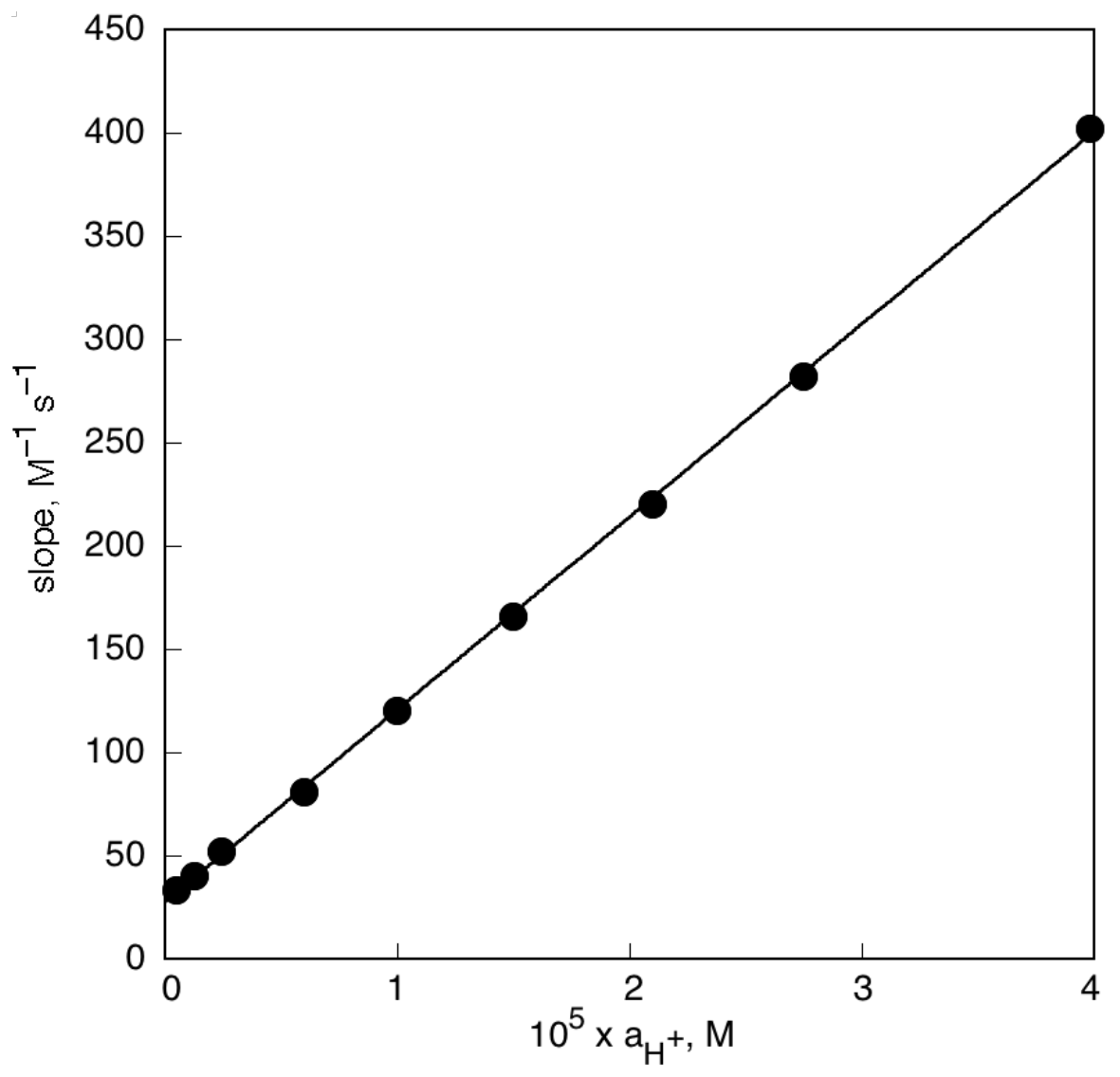

Figure S3. Reaction of $\mathbf{4 H}$ with aminoacetonitrile in water. Plots of slopes of buffer plots versus $\mathrm{a}_{\mathrm{H}^{+}}$according to eq 8 . 


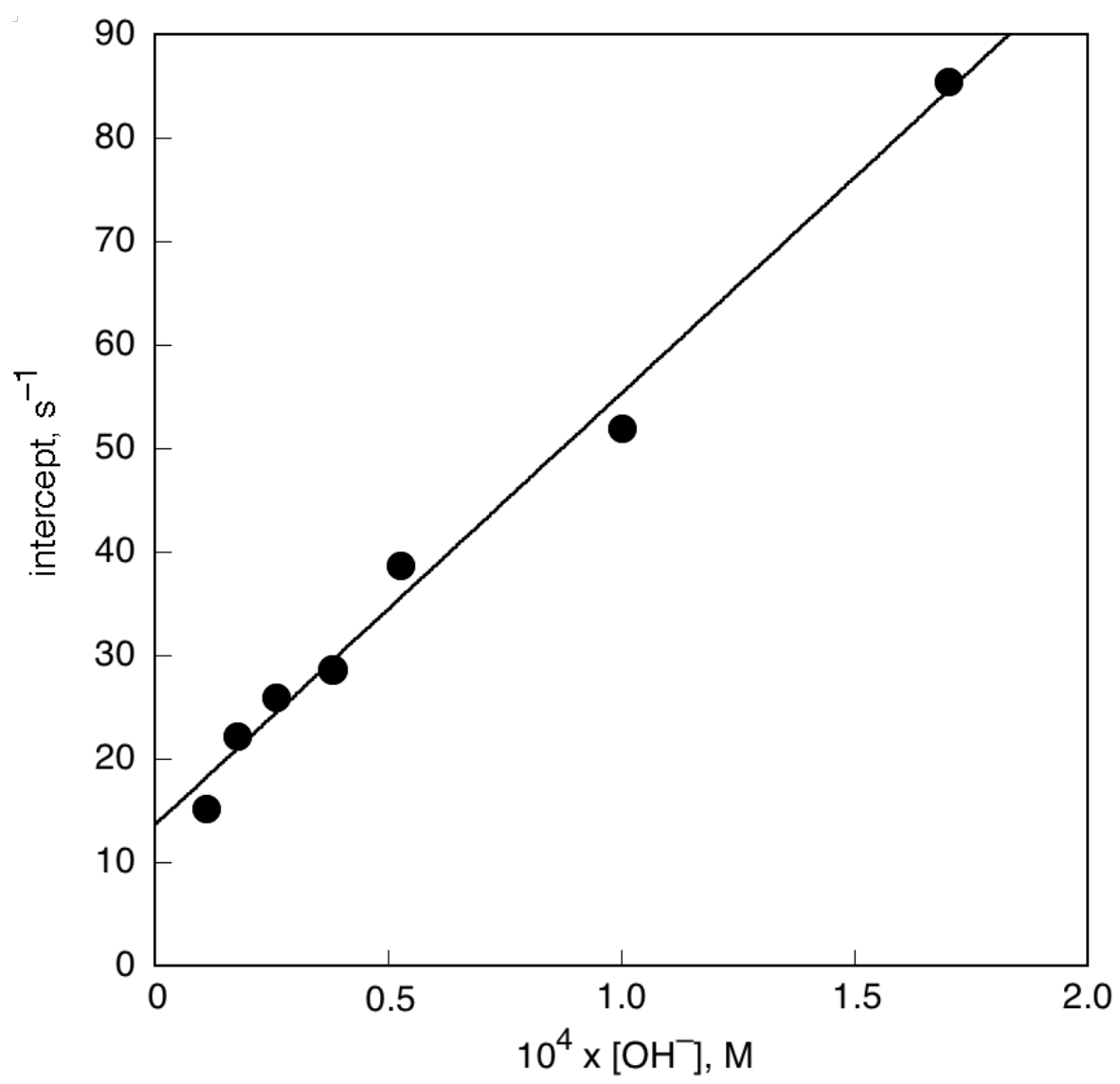

Figure S4. Plot of intercepts of buffer plots in piperidine buffers versus $\left[\mathrm{OH}^{-}\right]$in $50 \%$ DMSO-50\% water. The slope of this plot yields $k_{1}^{\mathrm{OH}}$. 